\title{
Validation of a prognostic score in critically ill patients undergoing transport
}

\author{
J F BION, S A EDLIN, G RAMSAY, S MCCABE, I MCA LEDINGHAM
}

\begin{abstract}
Fifty consecutive critically ill patients transported between hospitals by a mobile intensive care team were assessed prospectively using a modification of the acute physiology and chronic health evaluation (APACHE II) sickness scoring system. Assessments were made before and after resuscitation, on return to base, and after 24 hours of intensive care.

No patient died during transport. Twenty two patients died subsequently in hospital and 28 survived to return home. The mean score for the non-survivors before resuscitation was 21.7 and for the survivors 12.2 $(p<0.0005)$. Among the non-survivors there was a significant fall in score with resuscitation but this did not alter their subsequent outcome. Neither group deteriorated during transport.

The sickness score is a powerful method for determining prognosis, and employed longitudinally it may be useful in the assessment of treatment. It has important implications for the administration and organisation of regional intensive care services.
\end{abstract}

\section{Introduction}

For sound economic and therapeutic reasons increasing use is being made of prognostic scores in the management of critically ill patients. Several of these scoring methods have been developed with particular problems in mind, such as the sepsis score $^{1}$ and the Glasgow coma scale. ${ }^{2}$ Recently, however, a system has been developed which looks at a wide range of physiological indices: this is the acute physiology and chronic health evaluation (APACHE) score. ${ }^{3}$ This system weights these indices according to their degree of deviation from the norm; the weighted values are then scored and the sum of the scores is an expression of the degree of physiological derangement, regardless of the particular disease process. The original APACHE score used 34 variables, but this has now been refined and reduced to 12 -the APACHE II scoring system. ${ }^{4}$ This system has been extensively tested and validated between hospitals in the United States, and a modified form is now being employed in France. ${ }^{5}$

The following study is the first report of the use of this system in the United Kingdom, and was the first time that it had been employed longitudinally. The system has been modified slightly and is referred to as the sickness score. The modifications are not major and should not interfere with comparative studies using the APACHE II score. We have applied the sickness score to secondary referrals of critically ill patients from other hospitals, who are transported to central

Clinical Shock Study Group, Western Infirmary, Glasgow G11 6NT J F BION, MRCP, FFARCS, research fellow

$S$ A EDLIN, MRCP, FFARCS, research fellow

G RAMSAY, FRCS, research fellow

$S$ MCCABE, FRCS, research fellow

I MCA LEDINGHAM, FRCSED, FRCPGLAS, FRSE, professor

Correspondence to: Dr J F Bion. intensive care units using a specially modified ambulance staffed by two doctors. ${ }^{6}$ Because all transfers were between hospitals results of full biochemical analyses were available to allow collection of data for subsequent calculation of the sickness score.

\section{Methods}

Table I lists the 12 variables included in the modified APACHE II score (sickness score) together with their respective weightings. Additional weighting is given to age and previous chronic disease (table II). The following modifications have been made to the original score: (1) the values for serum creatinine have been converted to SI units; (2) haemoglobin is used instead of packed cell volume (haemoglobin is employed more commonly in Britain, and the values chosen approximate well to those of packed cell volume); (3) to assess oxygenation we employ a ratio between the percentage inspired oxygen concentration and the pressure of arterial oxygen $\left(\mathrm{PaO}_{2}\right)$ rather than the alveolar-arterial oxygen difference used in the APACHE II score. We have used this ratio, firstly, because it is a simple calculation to perform; secondly, because alveolar oxygen tensions are derived values and may be inaccurate in severe pulmonary disease; and, thirdly, because the ratio is an accepted method of calculating pulmonary shunting, and the values we have chosen are based on a shunt nomogram. The results obtained from the sickness score correspond well with those derived from the APACHE score, differing by no more than one point (unpublished data), and the modifications have been discussed in detail with the originators of the APACHE II score.

The sickness score was calculated for 50 consecutive patients transferred between hospitals. Data for calculating the score were collected at four time points: (a) on arrival of the team at the referring hospital; (b) after resuscitation, just before departure; (c) immediately on return to base; and $(d)$ after 24 hours of intensive care for those patients admitted to the Western Infirmary. Data were collected on a special form by any one of four doctors and analysed subsequently. At the end of transport cardiovascular variables were recorded as the ambulance drew to a halt. Blood gas analyses were made before changing ventilator settings. Variables with long time constants such as creatinine or haemoglobin concentration were assumed to be unchanged by resuscitation or transport if the patient's disease process had not affected these variables in any way. The Glasgow coma scale used was the best value obtained at any time during the team's care of the patient (usually two to five hours) unless sedation had interfered with the assessment; in that case a value was obtained by discussion with the referring medical staff.

All patients had intra-arterial pressure monitoring and electrocardiographic recordings throughout the period of the study. A Manley ventilator was used for controlled ventilation; fresh gases were provided via rotameters. Core temperature was measured using transducers or mercury thermometers.

Statistical analyses were by Student's $t$ test, $\chi^{2}$ test, and confidence intervals.

\section{Results}

Figure 1 shows the individual sickness scores of survivors and non-survivors at each of the four time points, together with the means, standard errors, and confidence intervals for the two groups.

No survivor scored more than 18. Six of the patients who subsequently died scored 18 or less; and of these, three had severe irreversible brain damage without other organ disease, one had incapacitating psychiatric disease requiring full nursing care in addition to his primary problem, and two died from unexpected complications at other hospitals. 


\begin{tabular}{|c|c|c|c|c|c|c|c|c|c|}
\hline & \multicolumn{9}{|c|}{ Score } \\
\hline & 4 & 3 & 2 & 1 & 0 & 1 & 2 & 3 & 4 \\
\hline $\begin{array}{l}\text { Core temperature }\left({ }^{\circ} \mathrm{C}\right) \\
\text { Mean blood pressure }(\mathrm{mm} \mathrm{Hg})^{*} \\
\text { Heart rate } / \text { min } \\
\text { Respiratory rate } / \mathrm{min} \\
\text { \% Inspired } \mathrm{O}_{2} / \mathrm{PaO}_{2}(\mathrm{kPa}) \\
\text { Arterial pH } \\
\text { Creatinine }(\mu \mathrm{mol} / \mathrm{l}) \dagger \\
\text { Sodium }(\mathrm{mmol} / \mathrm{l}) \\
\text { Potassium }(\mathrm{mmol} / \mathrm{l}) \\
\text { Haemoglobin }(\mathrm{g} / \mathrm{d}) \\
\text { White cell count }\left(\times 10^{\circ} / \mathrm{l}\right)\end{array}$ & $\begin{array}{l}\geqslant 41 \\
\geqslant 160 \\
\geqslant 180 \\
\geqslant 50 \\
\geqslant 5 \cdot 0 \\
\geqslant 7 \cdot 7 \\
\geqslant 600 \\
\geqslant 180 \\
\geqslant 7 \cdot 0 \\
\geqslant 18 \cdot 0 \\
\geqslant 40 \cdot 0\end{array}$ & $\begin{array}{l}39-40 \cdot 9 \\
130-159 \\
140-179 \\
35-49 \\
4 \cdot 0-4 \cdot 99 \\
7 \cdot 6-7 \cdot 69 \\
300-599 \\
160-179 \\
6 \cdot 0-6 \cdot 9 \\
=\end{array}$ & $\begin{array}{l}\overline{110}-129 \\
110-139 \\
\overline{2} \cdot 1-3 \cdot 99 \\
\overline{180-299} \\
155-159 \\
\overline{15} \cdot 0-17 \cdot 9 \\
20 \cdot 0-39 \cdot 9\end{array}$ & $\begin{array}{l}38 \cdot 5-38 \cdot 9 \\
\overline{2} \\
\frac{25-34}{7 \cdot 5-7 \cdot 59} \\
130-179 \\
150-154 \\
5 \cdot 5-5 \cdot 9 \\
14 \cdot 0-14 \cdot 9 \\
15 \cdot 0-19 \cdot 9\end{array}$ & $\begin{array}{l}36-38 \cdot 4 \\
70-109 \\
70-109 \\
12-24 \\
<2 \cdot 09 \\
7 \cdot 33-7 \cdot 49 \\
50-129 \\
130-154 \\
3 \cdot 5-5 \cdot 4 \\
9 \cdot 0-13 \cdot 9 \\
3 \cdot 0-14 \cdot 9\end{array}$ & $\begin{array}{l}34-35 \cdot 9 \\
\overline{10-11} \\
= \\
= \\
\bar{z} \cdot 0-3 \cdot 4 \\
=\end{array}$ & $\begin{array}{l}32-33 \cdot 9 \\
50-69 \\
55-69 \\
6-9 \\
7 \cdot 25-7 \cdot 32 \\
549 \\
120-129 \\
2 \cdot 5-2 \cdot 9 \\
6 \cdot 1-8 \cdot 9 \\
1 \cdot 0-2 \cdot 9\end{array}$ & $\begin{array}{l}\frac{30-31 \cdot 9}{40-54} \\
\overline{\overline{7}} \\
\overline{11} 15-7 \cdot 24 \\
= \\
=\end{array}$ & $\begin{array}{l}\leqslant 29 \cdot 9 \\
\leqslant 49 \\
\leqslant 39 \\
\leqslant 5 \\
\leq 7 \cdot 15 \\
=110 \\
\leqslant 2 \cdot 5 \\
\leqslant 6 \cdot 0 \\
<1 \cdot 0\end{array}$ \\
\hline
\end{tabular}

Glasgow coma scale Score as 15 - actual score

* Mean arterial pressure $(\mathrm{mm} \mathrm{Hg})=(2$ diastolic + systolic $) / 3$

$\dagger$ If acute renal failure has occurred, double score.

Conversion: SI to traditional units $-\mathrm{PaO}_{2}: 1 \mathrm{kPa} \approx 7.5 \mathrm{~mm} \mathrm{Hg}$. Creatinine: $1 \mu \mathrm{mol} / 1 \approx 0.01 \mathrm{mg} / 100 \mathrm{ml}$. Sodium: $1 \mathrm{mmol} / 1=1 \mathrm{mEq} / 1 . \mathrm{Potassium}: 1 \mathrm{mmol} / 1=1 \mathrm{mEq} / 1$.

TABLE II-Scores for age and chronic disease (from Knaus et al ${ }^{4}$ )

\begin{tabular}{lccccc}
\hline Age (years) & $\leqslant 44$ & $45-54$ & $55-64$ & $65-74$ & $\geqslant 75$ \\
Score & 0 & 2 & 3 & 5 & 6 \\
\hline
\end{tabular}

Chronic disease score

If chronic disease history is positive:

Elective postoperative patients score 2

medical patients score 5

Chronic disease category

1 Disease (a) must have been evident before this hospital admission; $(b)$ must be of sufficient severity to prevent independent self care

This category includes chronic dialysis, documented cirrhosis, or portal hyperpatient to the house

2 Immunosuppression: patients receiving chemotherapy, radiation long term low dose steroids, or short term high dose steroids; or malignant or other disease dose steroids, or short term high dose steroids; or malignant
which is sufficiently advanced to impair resistance to infection.

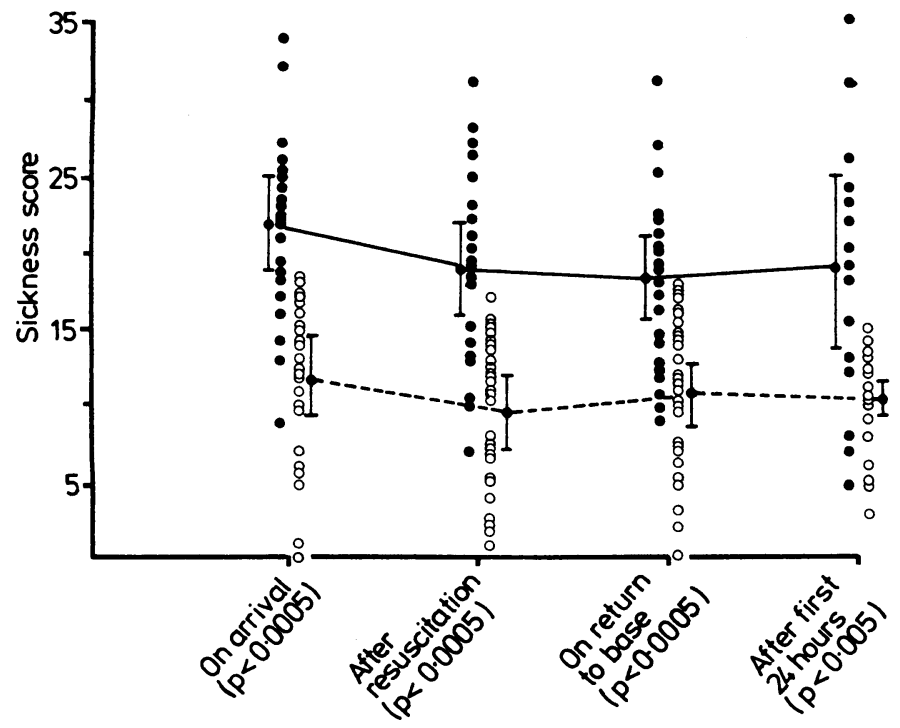

FIG 1-Individual sickness scores, mean values, and confidence intervals during resuscitation and transport of survivors $(O)$ and non-survivors $(\boldsymbol{O})$.

The differences in mean values between the two groups were highly significant. Although both groups showed a fall in score after resuscitation (and hence an improvement in physiology), this was significant only for the non-survivors between initial assessment and the end of transfer $(p<0.05)$. Neither group deteriorated during transport, though the survivors showed a small, insignificant rise in score. After 24 hours of intensive care the range of scores for the non-survivors had increased, showing the variability of response to treatment.

Differences between the two groups were analysed in greater detail by examining individual variables during the journey. Survivors showed a rise in score for more variables than the non-survivors. The most common change was a rise in heart rate greater than $110 /$ minute. This affected only those survivors who were intubated and probably represents a sympathetic response to stimulation during movement.

Distribution of the commoner diseases (table III) showed an expected preponderance of acute renal failure and sepsis among the non-survivors, confirming the high mortality associated with these conditions.

The predictive power of the sickness score was assessed by plotting the percentage actual death rate for different sickness score bands

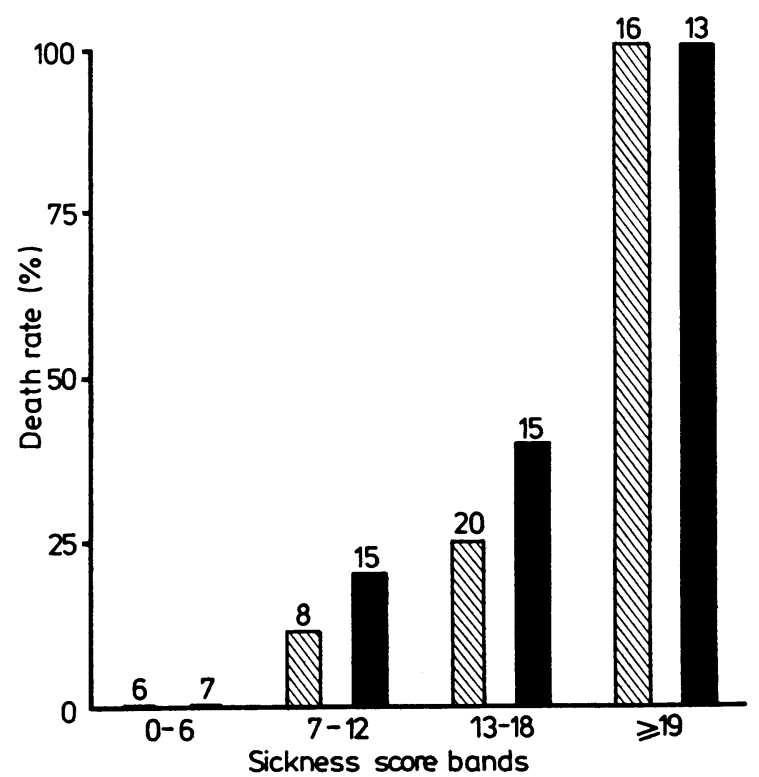

FIG 2-Percentage death rate for each sickness score band calculated before $\square$ and after $\square$ resuscitation. Numbers refer to total in each group.

TABLE III-Diseases present at initial resuscitation

\begin{tabular}{|c|c|c|}
\hline & $\begin{array}{c}\text { No }\left(\begin{array}{l}0 \\
o\end{array}\right) \text { of } \\
\text { survivors } \\
(n=28)\end{array}$ & $\begin{array}{c}\text { No }\left({ }^{0}\right) \text { of } \\
\text { non-survivors } \\
(n=22)\end{array}$ \\
\hline $\begin{array}{l}\text { Acute renal failure } \\
\text { Sepsis/septic shock } \\
\text { Trauma } \\
\text { Aspiration } \\
\text { Obstructive airways disease } \\
\text { Pneumonia } \\
\text { Aortic aneurysm } \\
\text { Other conditions }\end{array}$ & $\begin{array}{l}2(7 \cdot 1) \\
2(7 \cdot 1) \\
11(39 \cdot 3) \\
1(3 \cdot 6) \\
4(14 \cdot 3) \\
2(7 \cdot 1) \\
8 \frac{(28 \cdot 6)}{4}\end{array}$ & $\begin{array}{l}10(45 \cdot 5) \\
6(27 \cdot 3) \\
4(18 \cdot 2) \\
6(27 \cdot 3) \\
1(4 \cdot 5) \\
2(9 \cdot 1) \\
2(9 \cdot 1) \\
5(22 \cdot 7)\end{array}$ \\
\hline $\begin{array}{l}\text { Mean age in years (SD) } \\
\text { Resuscitation time in minutes (SD) }\end{array}$ & $\begin{array}{l}38 \cdot 0(20 \cdot 6) \\
87.5(50 \cdot 0)\end{array}$ & $\begin{array}{l}55.6(18.5) \\
98.8(47.0)\end{array}$ \\
\hline
\end{tabular}


calculated for the group of patients when first seen, and then recalculated after resuscitation but before transfer (fig 2 ). The results showed an increase in death rate with each rise in sickness score band. Death rates within the middle bands were higher on recalculation after resuscitation, rising from $25 \%$ to $40 \%$ in the $13-18$ band. This was in part because of a shift, with treatment, of the healthier patients into a lower band-that is, 7-12-and of the more severely ill patients from the upper band-that is, $\geqslant 19$.

\section{Discussion}

For these 50 patients an initial sickness score of 19 or more was invariably associated with subsequent death. Lower scores, however, did not necessarily ensure survival. This is not surprising in patients who develop complications later in their hospital stay. Severe single organ disease may not attract a high score, particularly if treatment has already been started. We emphasise that all these patients had already received the best care available at their referring hospitals. As treatment will influence the score, it is perhaps surprising that the two groups were so well defined, and it is a tribute to the power of the system that it could distinguish survivors and non-survivors so effectively.

Resuscitation and supportive treatment produced a significant fall in scores for the non-survivors but not for the survivors. This difference is attributable to various factors. Firstly, it is easier to produce a fall in score for certain variables than for others: a low $\mathrm{pH}$ is easily corrected with bicarbonate, and hypotension with plasma; but creatinine or serum sodium concentrations are unlikely to be influenced in the short term by treatment. Thus the greater the degree of physiological disturbance, and the more variables affected, the greater the possibility of effecting a reduction in score. Secondly, there is an irreducible minimum score in the weightings for age and chronic disease. Thirdly, the survivors were more stable, and changes in their condition tended to be too small to alter their score.

Transport was not associated with an appreciable rise in score, indicating the stability of these patients after adequate preparation for transfer and confirming our opinion that careful resuscitation is crucial before moving critically ill patients.

In those patients with an initial sickness score of 19 or more a reduction in score to less than 19 with treatment did not influence subsequent outcome. This suggests that the degree of physiological derangement had reached a stage at which damage to the organism was irreversible despite full supportive care. Supportive treatment in survivors provides time for spontaneous recovery to occur; in non-survivors support may sustain life but the capacity for repair has been lost. Our group of 50 patients, however, represented a selected population: they were those patients who required major supportive care because rapid and specific curative treatment was not available for their particular disease. Knaus has shown that the predictive power of the APACHE II score is poor for a disease such as acute diabetic ketoacidosis, in which a profound, life threatening metabolic disturbance can be rapidly reversed with specific curative treatment-insulin (paper in press). The prognostic power of the sickness score in our group of patients was due in part to the exclusion of conditions which were amenable to specific cure.

It is the initial score, before resuscitation, which is important in assessing prognosis. Difficulties may be experienced with certain components of the score, however. The heavily weighted Glasgow coma scale requires careful evaluation, and it is our practice to use the best value obtainable after resuscitation rather than that value obtained when the patient is first seen; this appears to give a more accurate reflection of cerebral function. Weighting for previous chronic disease adds either two or five points to the total score and requires that a careful history should be taken from the attending staff and relatives; Knaus does not include psychiatric disease in this category, but we consider that it is appropriate to class as a positive chronic disease history disease of any organ or system of sufficient severity to prevent independent self care. We shall examine this modification in subsequent studies.

The small sample size of this preliminary trial prevents didactic recommendations at this stage, and further studies are in progress to evaluate the accuracy and usefulness of the sickness score in managing the critically ill. This trial suggests that patients scoring 19 or more should not be transferred for admission to intensive care; this, however, ignores the fact that the score is not disease independent. It also ignores the possibility that advances in therapeutic management may salvage patients who might previously have died. At this stage the level at which admission to intensive care would be refused must be set higher than our scores suggest until the system has been evaluated and refined further. The system does, however, allow an assessment of probable outcome to be made by telephone, which is important if transfers over long distances are necessary.

Use and abuse of intensive care services has been the subject of a recent leading article. ${ }^{8}$ We believe that this study has validated the sickness score as an important prognostic tool, which will also be useful in auditing intensive care services. It has reinforced the safety of transporting stabilised critically ill patients and has important implications for the administration and organisation of regional intensive care services.

We are particularly grateful to Dr W A Knaus, director of ICU research at the George Washington University Medical Center, Washington, DC, USA, for many very helpful discussions and for allowing us access to previously unpublished material without which this trial could not have been performed. We also thank the nursing and medical staff of both the referring hospitals and the Western Infirmary for their help.

\section{References}

1 Elebute EA, Stoner HB. The grading of sepsis. Br f Surg 1983;70:29-31. Teasdale G, Jennett B. Assessment of coma and impaired consciousness. Lancet

$1974 ; \mathrm{ii}: 81-4$.
3 Knaus WA, Zimmerman JE, Wagner DP, et al. APACHE: acute physiology and chronic health evaluation: a physiologically based classification system. Crit Care Med 1981;9:591-603.

4 Knaus WA, Draper EA, Wagner DP. APACHE II: final form and national validation results of a severity of disease classification system. Crit Care Med $1984 ; 12: 213$. 5 Le Gall JR, Loirat P, Alperovitch A, et al. A simplified acute physiologic score for
ICU patients. Crit Care Med 1984;12:975-7.

6 Ledingham IMCA, Banks JG. Movement of the critically ill. Hospital Update 1980;28:43-9.

7 Waddell G, Scott PDR, Lees NW, Ledingham IMcA. Effects of ambulance transport in critically ill patients. Br Med $\mathcal{f} 1975 ; i: 386-9$.

$8 \mathrm{Jennett}$ B. Inappropriate use of intensive care [Editorial]. Br Med $\mathcal{Y} 1984 ; 289$ 1709-11.

(Accepted 16 May 1985)

\section{YEARS AGO}

An unhappy illustration of the danger attending the too common practice of blowing down the chimney of a partially filled oil-lamp, to extinguish the flame, has this week been afforded at Sedgley, where a married woman named Maria Lloyd met with a shocking death through endeavouring to extinguish a paraffin-lamp in this way. The lamp exploded, and ignited her clothing, and also that of her husband. The woman died after undergoing great agony. At the inquest on the body, a verdict of accidental death was returned. We recently called attention in these columns to the precautions which Sir Frederick Abel recommends to be observed, which would certainly have the effect of reducing, if they did not altogether remove, the risk of accidents attending the use of petroleum and paraffin oils. In order to safely extinguish an explosive lamp, it was pointed out that the flame should be lowered until only a flicker is visible, when the mouth should be brought to a level with the top of the chimney, and a sharp puff of breath projected across the opening. Had that plan been adopted in the present instance, there is little doubt that the accident, which in one case has been attended with fatal consequences, would never have occurred. (British Medical Fournal 1885;i:1071.) 